\title{
Downscaling heavy rainfall in the subtropics - a simple approach for dynamical nesting
}

\author{
H. Huebener ${ }^{1}$, K. Born ${ }^{2}$, and M. Kerschgens ${ }^{2}$ \\ ${ }^{1}$ Institute for Meteorology, Freie Universität Berlin, Germany \\ ${ }^{2}$ Institute for Geophysics and Meteorology, University of Cologne, Germany \\ Received: 31 July 2006 - Revised: 12 December 2006 - Accepted: 31 January 2007 - Published: 26 April 2007
}

\begin{abstract}
The simulation of local scale precipitation with nested models often suffers from large errors in the boundary rows. Advection of precipitation into the model domain of the small scale model can lead to an overestimation of precipitation in the boundary grid cells of the nested model and a drying of the interior grid area. Consequently, the finer scale structure of rainfall events of the small scale model can not evolve. These errors result from three main sources: "dynamical", "scale", and "parameterization" problems. As a first step to reduce the "parameterization" boundary errors, we propose a nesting procedure where rainwater from the driving larger scale model is converted to cloud water in the smaller scale model. The nesting method is applied to a case study of heavy rainfall in semi-arid southern Morocco. The results show the elimination of erroneous excessive rainfall in the boundary rows and slightly enhanced rainfall in the interior of the nested model domain. Additionally, fine scale structures in the precipitation patterns develop. The excessive surface runoff is clearly diminished in comparison to the standard nesting procedure. The proposed approach enables scale consistent precipitation patterns resulting from model physics and grid-resolution of the smaller scale model for the complete model domain.
\end{abstract}

\section{Introduction}

Determination of temporal and spatial distribution of rainfall is of special interest in subtropical semi-arid environments. In general, surface observations are scarce in these regions. Thus, the accuracy of available rain gauge data sets is limited and makes the calibration of remotely sensed products difficult (cf. Ali et al., 2005 and further references therein). In arid and semi-arid regions satellite estimated rain rates are

Correspondence to: H. Huebener

(huebener@met.fu-berlin.de) not always highly correlated with ground precipitation especially in mountainous areas and for short time scales (Nezlin and Stein, 2005). It is, however, essential to determine precipitation amounts correctly in space and time, particularly in these regions, to enable maximum use of the water and prevent disasters caused by extreme rainfall events.

Violent convective rainfall events are normally not displayed by GCM simulations, thus calling for dynamical or empirical downscaling. For empirical downscaling long data series of high quality are necessary to tune and validate the procedure. Since such data sets are often not available in arid and semi-arid regions, dynamical downscaling is the best available option. However, dynamical downscaling is particularly vulnerable to errors associated with the lateral boundary conditions (LBC), either at the inflow- or at the outflow boundary (e.g. Noguer et al., 1998). Three important sources of errors arising from boundary conditions are well known and have to be addressed in the downscaling approach: the "dynamic" problem, causing unrealistic wind field convergence near lateral boundaries, and a "parameterization" problem, arising from different parameterizations each adapted correctly to the addressed model scale - in the large scale and in the nested model. A third source of errors occurring in downscaling studies is the "scale-effect" due to the fact that parameterizations may act scale-dependent. This is a problem of the conception of dynamical downscaling and is observed (in the LM-to-LM downscaling), but not discussed in detail in the present study.

Firstly, the "dynamic" problem has always to be solved in limited area atmospheric modelling. Without nesting, the dynamic problem can be circumvented by different methods of boundary treatment, e.g. Dirichlet, Neuman or radiation boundary conditions (see e.g. Roache, 1972). In nested models, treatment of boundaries is somewhat more problematic: On one hand, the boundary cells should adapt to the large scale forcing values, on the other hand, model scale variability shall not be suppressed. Here, two methods were

Published by Copernicus GmbH on behalf of the European Geosciences Union. 


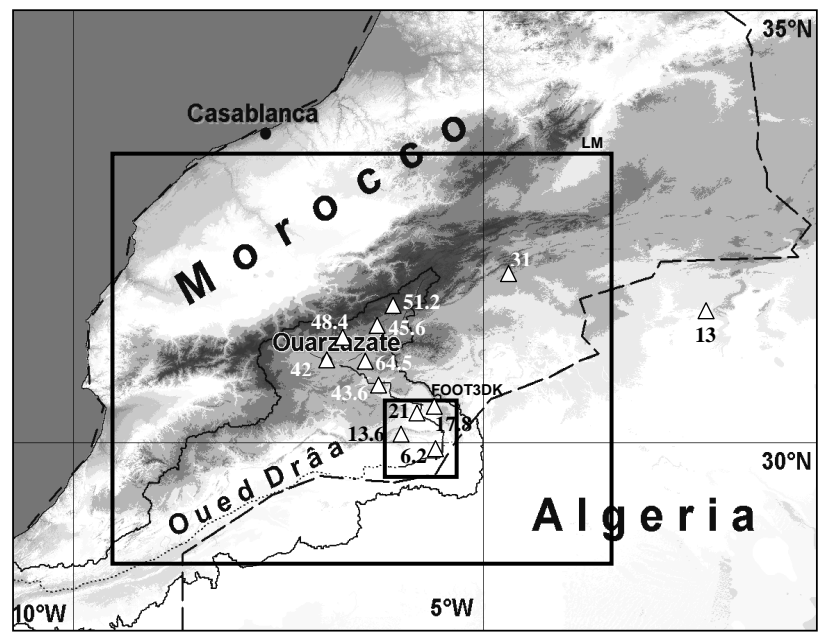

Fig. 1. Moroccan orography (shaded) and river catchment of the wadi Drâa (thin line). Triangles and numbers: Observed $24 \mathrm{~h}$ rainfall 2002/03/31 06:00 UTC-2002/04/01 06:00 UTC. Rectangles: LM $7 \mathrm{~km}$ resolution (large) and FOOT3DK (small) simulation domain.

mainly developed. In the widely used Davies-Nudging technique (Davies, 1976) the fields in the boundary rows are forced towards the values of the driving, larger scale model. This forcing is applied with decreasing weights for increasing distance from the boundary. The only concurrence to the Davies-Nudging is the spectral nudging (von Storch et al., 2000), where large scale components of the nested model are drawn towards forcing values in order to keep the larger scale development consistent in the two models. Spectral nudging is mainly applied to climatic time scales, whereas the Davies-Nudging is commonly used in numerical weather predictions. The solution to the "dynamical" problems has to be adapted individually to the models and scales used.

The second source of errors, the "parameterization" problem, is addressed in the present study. On different scales, atmospheric models have to use different, scale adapted parameterizations. In our case, the effect of differing cloud and convection parameterizations leads to extreme precipitation at the inflow boundary of the nested model. The "parameterization"nesting problem arises also for other parameterization like turbulence, but is of smaller impact. In our experience, the effect of cloud- and rainwater nesting is too strong to be ignored.

The "scale" problem can also cause inconsistencies between the precipitation in the driving model and the nested model. These can also occur when the parameterizations used are identical.

All the problems mentioned here can cause considerable errors in the formation of rainfall at in- and outflow boundaries. Errors in the precipitation signal can propagate far into the interior of the simulation domain (Wu et al., 2005). Overestimation of rainfall in the boundary rows leads to un- derestimation of moisture in the interior of the simulation domain and vice versa. The problem is usually circumnavigated by moving the lateral boundaries sufficiently far from the research area (Warner et al., 1997). As pointed out by Laprise (2003), this distance should theoretically encompass twice the propagation length of the fastest wave resolved in the model to ensure independence from the LBC.

We will present a simple method to reduce the "parameterization" type of boundary error for dynamically downscaled precipitation. The approach presented here is based on the general idea to enable the exchange of cloud and rain properties that are consistent with the physical parameterizations in both participating models. Therefore we propose to base the exchange of rainfall related fields on the basic field instead of the derived precipitation quantities. Concretely, we propose to provide the sum of cloud water and rainwater from the driving model as cloud water to the nested model. This quantity has the benefit of being physically sensible to process in different cloud and precipitation parameterizations, not only for the models used in this study, but probably for other combinations of models and parameterizations as well.

As case study we use an event of heavy rainfall in southern Morocco. Since the study focuses on the problems arising from the nesting technique, we do not predominantly aim at a careful evaluation of the model performance, which would be a study on its own. Nevertheless, we compare model results at least qualitatively with observations from satellite and climate stations in order to be sure that the model forecast produces consistent results.

In section two of this paper we briefly describe the rainfall event used as case study. We introduce the model chain used for the simulations and two different nesting approaches in section three. In the next section results are presented and compared to ground measurements. Finally, the results are discussed and further research ideas are given in section five.

\section{Description of the rainfall event}

Thunderstorms and a lee cyclogenesis south of the Atlas Mountains between 30 March 2002 and 1 April 2002 caused rainfall amounts of $42 \mathrm{~mm}$ in $24 \mathrm{~h}$ at the station Ouarzazate (WMO No $60265,30^{\circ} 56^{\prime} \mathrm{N}, 6^{\circ} 54^{\prime} \mathrm{W}$ ). This constitutes the largest rainfall event since beginning of measurements at this station in 1978. Nested simulations are performed for the period 30.03.2002, 12:00 UTC to 01.04.2002, 00:00 UTC. Further ground based measurements, transecting from the High Atlas Mountain tops to the border of the Saharan desert, are provided by the research project IMPETUS (Fig. 1) and allow for a visual comparison of model results and observed rainfall.

Satellite observations (Fig. 2) show that the small scale structure of the rainfall event can not be deduced solely from METEOSAT images, it is only depicted by the microwave signal obtained from the polar orbiting satellites. Since the 

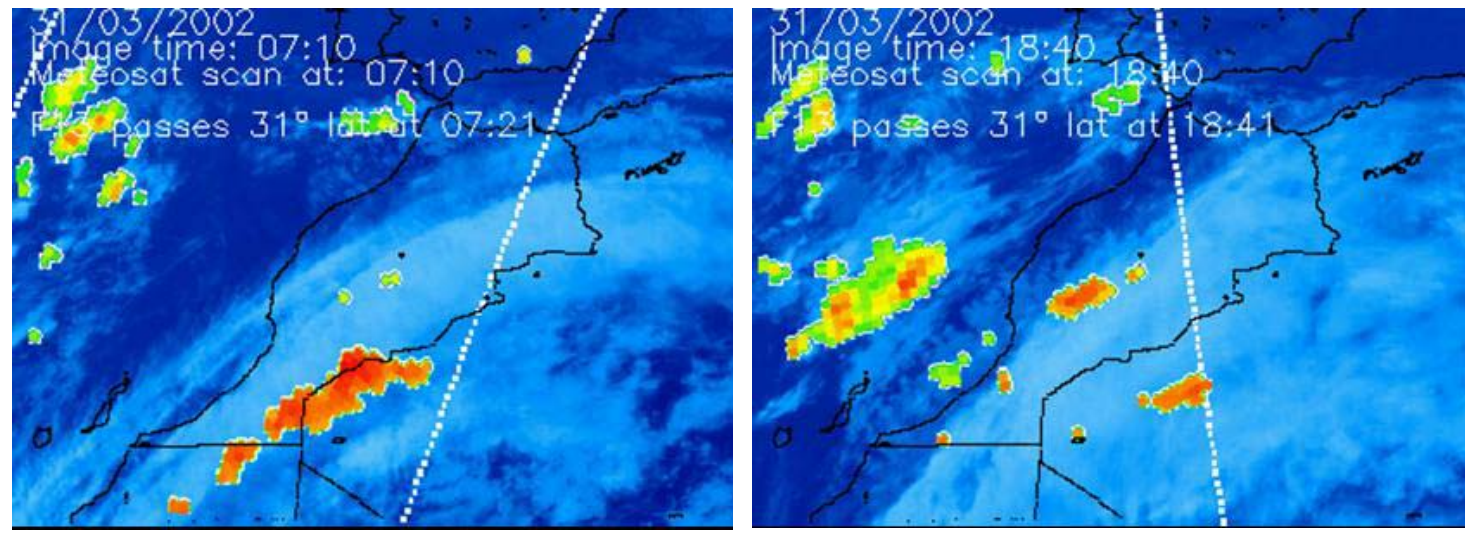

Fig. 2. Satellite images: METEOSAT IR (blue) and polar orbiting F13 micro wave sounding (small structures) at 31/03/2002 07:10 UTC (a) and 18:40 UTC (b).

latter are only available twice daily (when a polar orbiting satellite passes the region), the temporal resolution is not sufficient for a detailed analysis.

The synoptic situation during the case study represents a classical cyclogenetic situation with three driving forces:

- intrusion of air with high PV values from an upper air trough,

- destabilisation of the atmosphere in the warm sector of the developing cyclone by slantwise convection and orographic lifting

- feeding of the developing circulation with energy by advection of warm and moist air.

For a further description of the event see Fink and Knippertz (2003). The strong synoptic forcing is promising for simulating the situation correctly on a smaller scale even without assimilation of additional observational data.

\section{Downscaling procedure}

The forcing of our model chain is taken from analysis data from the global numerical weather prediction model GME of the German Weather Service (DWD). The analysis data is used to drive simulations with the non-hydrostatic limited area model Lokal Modell (LM) of the DWD with $0.25^{\circ}$ lat/lon resolution in north-western Africa $\left(0^{\circ}-35^{\circ} \mathrm{N}, 10^{\circ} \mathrm{E}-\right.$ $25^{\circ} \mathrm{W}$ ). Dynamical downscaling to $0.0625^{\circ}$ lat/lon resolution is realised with the LM centred in the Atlas Mountains $\left(29^{\circ} \mathrm{N}-34^{\circ} \mathrm{N}, 9.5^{\circ} \mathrm{W}-3.5^{\circ} \mathrm{W}\right.$, large rectangle in Fig. 1). In a further step high resolution simulations $(3 \mathrm{~km} \times 3 \mathrm{~km})$ are performed using the non-hydrostatic mesoscale model FOOT3DK for a region at the desert border $(29.5 \mathrm{~N}-30.5 \mathrm{~N}$, $5.5 \mathrm{~W}-6.5 \mathrm{~W}$, small rectangle in Fig. 1). A one-way-nesting is applied, using buffer zones at the lateral and upper boundaries to minimise errors due to an abrupt scale change (cf.
Davies, 1976). FOOT3DK simulations start with a one hour diastrophic phase where the coarse resolution orography is gradually nudged towards the high resolution orography to avoid aliasing when the flow adapts to the high resolved orography.

The original intention for the application of the nesting procedure LM-FOOT3DK was to simulate small scale soilvegetation-atmosphere interactions more realistic than with the larger scale model LM. In addition to the finer grid resolution and the appropriate cloud and rain parameterization, a more sophisticated SVAT scheme is used in FOOT3DK. Therefore, physical parameterizations in LM and FOOT3DK are different. Regarding to the atmospheric water cycle, variables interpolated from the coarse grid to the fine grid are expected to cause problems, since thresholds like e.g. the maximum cloud water content may differ between different cloud and convection parameterizations. In the LM, an original warm-rain scheme after Kessler (1969) extended by an ice phase computes the grid-scale moisture and rainfall (Doms and Schättler, 2006). The convection parameterization is based on the Tiedtke-scheme (Tiedtke, 1989). The basic characteristics of the models are listed in Table 1.

In FOOT3DK, the grid-scale cloud parameterization is based on the Sundquist-scheme (Sundquist, 1988) and enhanced for a consistent parameterisation of precipitation formation in both stratiform and convective clouds (Sogalla and Kerschgens, 2001). The convection scheme in FOOT3DK, as in the LM, is based on the Tiedtke (1989) parameterisation. The original mass flux closure of the scheme yields too small moisture flux through the cloud base in case of positive but weak moisture convergence and/or grid-scale ascent (Sogalla and Kerschgens, 2001). Thus, in FOOT3DK the closure at the cloud base uses a combined criterion where mass flux through the cloud base is calculated with the CAPEcriterion (Nordeng, 1994) and only the activation of precipitation is derived from the original Tiedtke-scheme. For applications on the mesoscale the convection scheme is extended 
Table 1. Basic characteristics of the models LM and FOOT3DK with emphasis on cloud and precipitation parameterizations.

\begin{tabular}{|c|c|c|}
\hline & Lokal-Modell & FOOT3DK \\
\hline Dynamics & Non-hydrostatic & Non-hydrostatic \\
\hline Turbulence & $\begin{array}{l}\text { Prognostic TKE with Mellor-Yamada level } 2.5 \\
\text { approximation }\end{array}$ & $\begin{array}{l}\text { Prognostic TKE with Mellor-Yamada level } 2.5 \\
\text { approximation }\end{array}$ \\
\hline Vegetation and soil & $\begin{array}{l}\text { Two-layer soil model (Jacobsen and Heise, } \\
\text { 1982) with annual cycle at lower boundary. } \\
\text { Penman-Monteith type transpiration (Jarvis, } \\
\text { 1976) and snow and interception storage. }\end{array}$ & $\begin{array}{l}\text { Two-layer soil model (Jacobsen and Heise, } \\
\text { 1982) with annual cycle at lower boundary, ad- } \\
\text { ditional groundwater (Huebener et al., 2005). } \\
\text { Penman-Monteith type transpiration (Jarvis, } \\
\text { 1976) and snow and interception storage. }\end{array}$ \\
\hline Surface & $\begin{array}{l}\text { Constant flux layer parameterization based on } \\
\text { the Louis (1979) scheme }\end{array}$ & $\begin{array}{l}\text { Extended Force-Restore method (Deardorf, } \\
\text { 1978; Jacobsen and Heise, 1982; Noilhan and } \\
\text { Planton, 1989) }\end{array}$ \\
\hline Cloud parameterization & $\begin{array}{l}\text { Modified Kessler (1969) warm rain scheme, } \\
\text { improved by including cloud ice phase }\end{array}$ & $\begin{array}{l}\text { Cloud microphysics after Sundquist (1988), } \\
\text { improved to consistently handle stratiform } \\
\text { and convective precipitation (Sogalla and Ker- } \\
\text { schgens, 2001). Subgrid condensation scheme } \\
\text { based on Sommeria and Deardorff (1977) and } \\
\text { Redelsperger and Sommeria (1986) }\end{array}$ \\
\hline Convection parameterization & Massflux scheme after Tiedtke (1989) & $\begin{array}{l}\text { Massflux scheme after Tiedtke (1989), com- } \\
\text { bined closure using massflux (Tiedtke, 1989) } \\
\text { and CAPE criteria (Nordeng, 1994; Sogalla and } \\
\text { Kerschgens, 2001). Hybrid scheme after Frank } \\
\text { and Cohen (1987) }\end{array}$ \\
\hline Radiation & $\begin{array}{l}\delta \text {-two-stream approximation (Ritter and Ge- } \\
\text { leyn, 1992) with cloud-radiation feedback }\end{array}$ & $\begin{array}{l}\text { Two-stream approximation (Kerschgens et al., } \\
\text { 1978) for cloudy atmosphere. }\end{array}$ \\
\hline
\end{tabular}

to a hybrid version (Frank and Cohen, 1987) where the updrafts are parameterised and the downdrafts are calculated explicitly. This approach yields optimal results in combination with a three dimensional transport scheme for precipitation and a subgrid-scale condensation scheme based on Sommeria and Deardorff (1977) and Redelsperger and Sommeria (1986).

The model FOOT3DK is nested into LM forecasts using the Davies-Nudging applied to the dynamic variables. For water vapour, cloud water and rainwater, two different nesting approaches are compared: In a control simulation (in the following: "CTRL"), the standard Davies-nesting procedure is used, where coarse grid cloud water and rainwater are prescribed at the boundary cells with exponentially decreasing influence towards the inner model domain. In the other simulation (in the following "RWtoCW"), the sum of rainwater and cloud water of the LM is supplied as total liquid water (cloud water) to FOOT3DK. The reason for this treatment is the different formulation for the conversion from cloud water to rainwater in the models, which leads to different maximum cloud water thresholds. The difference in cloud parameterizations produces unrealistically high rainfall rates at the inflow-boundaries in the CTRL simulation, reducing the total amount of liquid water in the inner model domain nearly to zero. In "RWtoCW", the cloud parameterization of FOOT3DK is able to produce rainwater more consistent with the assumptions of the parameterization. We cannot rule out an additional "scale-effect" for sure. However, in the next section we show a possible solution of the "parameterization" effect, succeeding to considerably reduce the erroneous rainfall in the boundary rows. Therefore we conclude the "scale" effect to be of minor importance in this case than the "parameterization" effect.

\section{Results}

Simulated precipitation by the LM for $0.25^{\circ}$ resolution (Fig. 3a) shows a pronounced precipitation signal between $25^{\circ}$ and $30^{\circ} \mathrm{N}$ around $10^{\circ} \mathrm{E}$ with maximum values around $75 \mathrm{~mm} / \mathrm{d}$. Unfortunately, no observations are available from the regions where the maxima occur. The performance of the model simulation can only be evaluated qualitatively by comparison with satellite observations (Fig. 2). Surrounding synoptic stations show that the pattern is similar to near surface observations (accumulated precipitation 2002/03/30 18:00 UTC-2002/04/02 00:00 UTC: Sidi Ifni, WMO No 

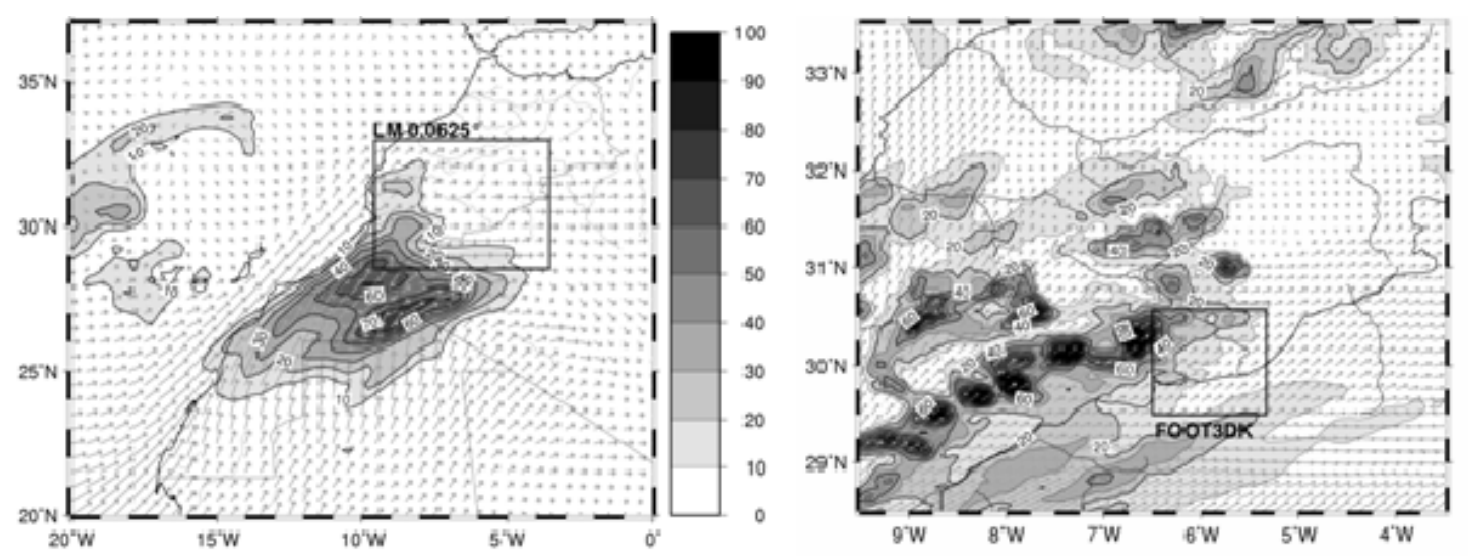

Fig. 3. $\mathrm{LM}$ simulated $24 \mathrm{~h}$ rainfall (mm/day, colours) for $31 / 03 / 2002$ (a) $0.25^{\circ}$ resolution (wind in $700 \mathrm{hPa}$, barbs), in (b) $0.0625^{\circ}(7 \mathrm{~km})$ resolution (wind in $950 \mathrm{hPa}$, barbs).

$60060,29^{\circ} 22^{\prime} \mathrm{N}, 10^{\circ} 11^{\prime} \mathrm{W}, 26 \mathrm{~mm}$; Tindouf, WMO No $60656,27^{\circ} 40^{\prime} \mathrm{N}, 8^{\circ} 08^{\prime} \mathrm{W}, 25 \mathrm{~mm}$; Bir Moghrein, WMO No $61401,25^{\circ} 14^{\prime} \mathrm{N}, 11^{\circ} 37^{\prime} \mathrm{W}, 11 \mathrm{~mm}$; data taken from Fink and Knippertz, 2003), but the rainfall in the middle Drâa valley and the High Atlas Mountains is clearly underestimated. The maximum rainfall is located too far south and not at the southern slopes of the High Atlas, as the IMPETUS stations suggest (Fig. 1). Additionally, the simulation misses the spatial fine scale structure of the event. Downscaled to $7 \mathrm{~km}$ resolution the precipitation pattern becomes better resolved and a tongue of extreme rainfall rates (up to $140 \mathrm{~mm} / \mathrm{d}$ ) extends further northeast-ward, but still the High Atlas Mountains show an unrealistic minimum (Fig. 3b). The LM model simulations are carried out using the same parameterizations. Therefore, the difference arising here is due to the "scale-effect". In the $0.25^{\circ}$-simulation, where unstable stratification is mainly removed by the convection parameterization, no convective cells are simulated on the model scale. Since the non-hydrostatic LM is able to deal with unstably stratified layers, the smaller scale LM simulation shows the development of single convective events, which are resolved by the model grid. Because the parameterizations are highly non-linear, the different behaviour results in much stronger local rainfall rates on the smaller scales. In addition, the directly simulated convection cells have a non-local lifecycle and are able to penetrate far into the Middle Drâa region, whereas the convection parameterization and according rainfall in the $0.25^{\circ}$ simulation is bound to the grid cell where instability first occurs. The fact that no boundary errors occur in the rainfall fields in the LM-to-LM nesting step suggests the "scale" problem to be of minor importance in this regard, compared to the "parameterization" problem turning up in the LM-to-FOOT3DK nesting step.

The LM rainfall pattern in the FOOT3DK simulation area matches quite well with the observations. Thus, the LM simulation with $7 \mathrm{~km}$ resolution seems to provide a suffi- cient forcing data set for the smaller scale simulation with FOOT3DK.

FOOT3DK simulations with $3 \mathrm{~km}$ resolution are conducted using the two nesting methods explained above. In the CTRL simulation, unrealistic rainfall rates are found at the inflow boundaries at the western and southern border of the nesting area (Fig. 4a, compare $700 \mathrm{hPa}$ wind from Fig. 3b). When all boundary rows that seem to be dominated by the LBC precipitation error are excluded, only a small part of the interior model area remains for analysis. Here nearly no rainfall is simulated except near the northeastern corner. This seems to be a consequence of the fact that the FOOT3DK cloud parameterization is not able to cope with high amounts of rainwater from the LM. Obviously, the boundary errors dominate the results and the atmospheric moisture in FOOT3DK is predominantly lost in the boundary rows. In the RWtoCW simulation only minimal precipitation is simulated in the southern and western inflow boundary rows (Fig. 4b). In the interior of the model area precipitation is slightly enhanced and band-like structures develop that correspond to the simulated cloud structures during the day (not shown). The observed rainfall at the stations El Miyit (EMY, 30 $21^{\prime} 50^{\prime \prime} \mathrm{N}, 5^{\circ} 37^{\prime} 44^{\prime \prime} \mathrm{W}$ ), Asrir (ASR, 30 $21^{\prime} 25^{\prime \prime} \mathrm{N}, 5^{\circ} 50^{\prime} 10^{\prime \prime} \mathrm{W}$ ), Jebel Hussein ou Brahmin $\left(29^{\circ} 56^{\prime} 12^{\prime \prime} \mathrm{N}, 5^{\circ} 37^{\prime} 43^{\prime \prime} \mathrm{W}\right.$ ) and Lac Iriki (IRK, 29 $58^{\prime} 23^{\prime \prime} \mathrm{N}$, $\left.6^{\circ} 20^{\prime} 57^{\prime \prime} \mathrm{W}\right)$ is better represented in the RWtoCW simulation for EMY and ASR, no change is found for JHB, while for IRK the CTRL simulation gives better results. However, since the high precipitation values in the boundary rows in the CTRL simulations are probably due to the nesting error this station should be viewed with caution.

To evaluate the simulations, moisture budgets are compared for the runs. In Fig. 5 the simulated $24 \mathrm{~h}$ surface runoff is compared, calculated from accumulated precipitation $(\mathrm{P})$, evapotranspiration $(\mathrm{E})$ and soil moisture $(\mathrm{SM})$ change (P-ESM: 2002/31/03 24:00 UTC minus 00:00 UTC). The result- 

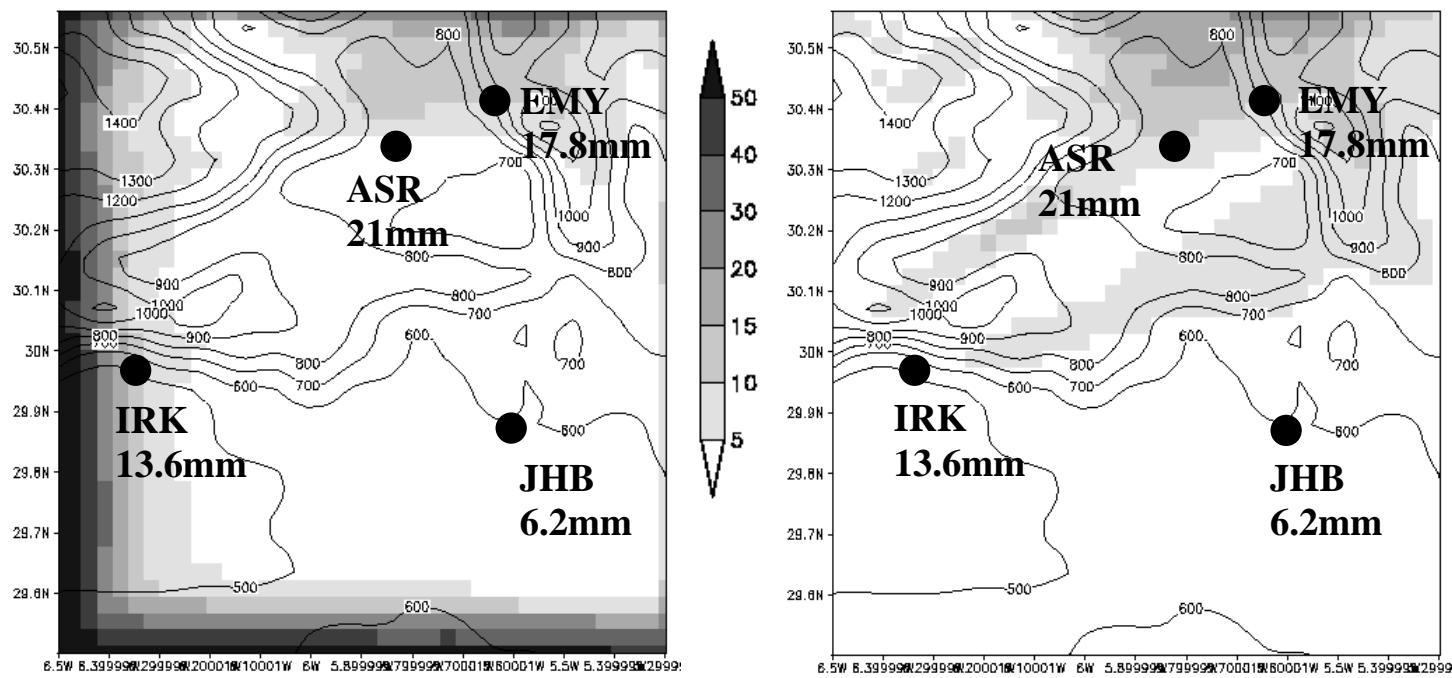

Fig. 4. Simulated $24 \mathrm{~h}$ precipitation (2002/03/31, 00:00 UTC-24:00 UTC) (mm/day) for (a) CTRL, (b) RWtoCW simulations.
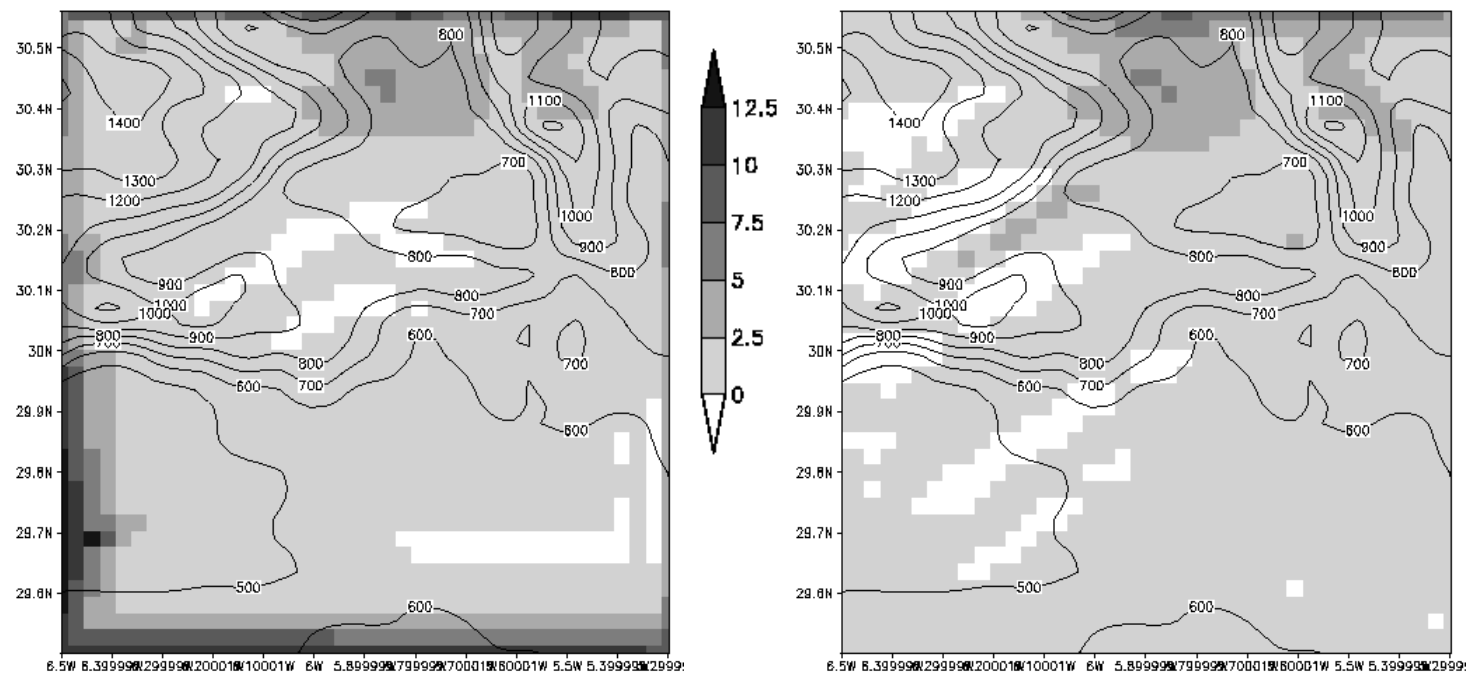

Fig. 5. $24 \mathrm{~h}$ surface runoff (mm/day) (P-E-SM) for (a) CTRL, (b) RWtoCW simulations.

ing moisture loss can be interpreted as surface runoff that is not treated in the model. Thus, the model concept does not provide a closed hydrological cycle: The surface runoff is just a sink of liquid water. This problem occurs in a great number of atmospheric models, since they are not built to simulate surface and subsurface water flow. The excessive erroneous rainfall in the boundary rows of the CTRL simulation is lost via surface runoff (Fig. 5a). In the RWtoCW simulation (Fig. 5b) the loss due to surface runoff is minimised compared to the CTRL simulation.

To complete the moisture budget evaluation, moisture advection $(q * v)$ has been calculated for the two cases (not shown). The comparison shows the same effect as the P-ESM balance. In both cases, moisture is lost due to the surface runoff, but the loss is reduced in the RWtoCW simulation compared to the CTRL simulation. Thus, for the RWtoCW simulation, the imbalance of the hydrological cycle is less pronounced compared to the CTRL simulation.

\section{Discussion and conclusion}

The simulation of local scale precipitation using different nested models suffers, despite other problems, from artificial convergences at boundary cells ("dynamic" problem), from differences in cloud and rain parameterizations ("parameterization" problem) and from scale inconsistency in the formation of precipitation ("scale" problem). The dynamic 
problem can be reduced or circumvented by moving boundary cells as far as possible from the area of interest (e.g. Warner et al., 1997; Laprise, 2003). The "scale" problem is of very basic nature and can not be avoided easily, because atmospheric phenomena develop differently in models using different scales. This is, of course, a motivation for downscaling and represents partly a desired effect. The "parameterization" problem may occur in different characteristics when using different models. In the case presented here, different cloud parameterizations cause unrealistic high rainfall amounts in the boundary zone of the nested model. A simple procedure to allow for physically consistent results is proposed in the present study.

There exist different possible approaches to initialize precipitation in the nested model, if the driving, larger scale model produces precipitation in a grid cell overlapping with the smaller scale modelling domain. A conventional straight forward approach is to interpolate all available variables from the larger scale model to the small scale model. For the nesting LM-FOOT3DK, applying this procedure to rainwater results in an overestimation of precipitation in the boundary grid cells of the nested model and to a drying of the interior simulation area. In addition, the finer scale structure of rainfall events of the small scale model is not accounted for due to the not scale consistent forcing at the boundaries. We propose to go one step back in the parameterization of rainwater formation and to convert rainwater from the larger scale model (LM) into cloud water in the nested model (FOOT3DK, "RWtoCW" simulation), in order to allow a physically consistent development of cloud and rainwater.

The RWtoCW simulation eliminates the erroneous excessive rainfall in the inflow boundary rows and more and finer resolved precipitation patterns in the interior model domain develop. Due to the model formulation, the moisture budget is not completely closed; the remaining imbalance of the model water cycle is interpreted as surface runoff that is not accounted for in the model.

Since the rainwater content of clouds may differ largely between different cloud parameterizations, this kind of problem is expected to occur similarly at any model combination using differing cloud parameterizations. The proposed technique may not be sufficient to solve rainfall related boundary error problems in all other model combinations, but it is easy to apply and believed to be a possible solution for the "parameterization" problem occurring in different model nesting combinations. Dynamical downscaling studies have to adapt the interpolation technique carefully to the needs of the model combination, not only regarding dynamical considerations at boundaries, but also to account for different physical parameterizations.

Another "scale" problem of the nesting procedure, which has not been addressed in this study, leads to an underestimation of rainfall amounts. It results from the fact that the larger scale model atmosphere is stabilized by the convec- tion parameterization. In the example presented here feeding the LM atmospheric parameters into FOOT3DK leads to a lesser amount of CAPE in the smaller scale model and reduces the orographic initiation of convective rain. Therefore, the procedure proposed here still leads to an underestimation of rainfall in the vicinity of the boundary rows because (1) the cloud water needs to be conversed into rainwater again and (2) the cloud base mass flux in FOOT3DK, calculated from CAPE, is underestimated. The vertical distribution of rainwater below the cloud base might result in downstream displacement of the precipitation signal, since this moisture has to be lifted to be conversed to rainwater again.

The proposed nesting approach is a first step to get to grips with the LBC problem in dynamical downscaling to improve the use and reliability of the results. In a next step it should be evaluated whether the proposed nesting improves the performance for all cases or only for the cases with strong rainfall advection at the inflow boundaries. A comparison study using the high-resolution LM $(2.8 \mathrm{~km})$ for the final downscaling step would give valuable information on the attribution of the error to the different possible causes ("parameterization" versus "scale" problem). Future research should also evaluate whether the "scale" problem for the CAPE can be reduced.

Acknowledgement. The authors wish to thank the German Weather Service (DWD) for providing GME analyses and computing time for the LM runs. This work was partly funded by the Federal German Ministry of Education and Research (BMBF) under grant no. 01 LW 301A and by the Ministry of Science and Research (MWF) of the federal state of Northrhine-Westphalia under grant no. 223-21200200. The authors wish to particularly thank one anonymous reviewer for useful comments and questions that helped to improve the overall paper.

Edited by: S. C. Michaelides and E. Amitai

Reviewed by: anonymous referees

\section{References}

Ali, A., Amani, A., Diedhiou, A., and OLebel, T.: Rainfall estimation in the Sahel. Part II: Evaluation of rain gauge networks in the CILSS countries and objective intercomparison of rainfall products, J. Appl. Meteorol., 44, 1707-1722, 2005.

Davies, H. C.: Lateral boundary formulation for multilevel prediction models, Q. J. R. Meteorol. Soc., 102, 405-418, 1976.

Deardorff, J. W.: Efficient prediction of ground surface temperature and moisture, with inclusion of a layer of vegetation, J. Climate, 1, 1096-1097, 1978.

Doms, G. and Schättler, U.: Description of the Nonhydrostatic Regional Model LM. Part II: Physical Parameterizations, Postfach 100465, 63007 Offenbach, Germany, Deutscher Wetterdienst (German Weather Service, DWD), Offenbach, 2006.

Fink, A. H. and Knippertz, P.: An extreme precipitation event in southern Morocco in spring 2002 and some hydrological implications, Weather, 58, 377-387, 2003. 
Frank, W. M. and Cohen, C.: Simulation of tropical convective systems. Part I: A cumulus parameterization, J. Atmos. Sci., 44, 3787-3799, 1987.

Huebener, H., Schmidt, M., Sogalla, M., and Kerschgens, M.: Simulating evapotranspiration in a semi-arid environment, Theor. Appl. Climatol., 80, 153-167, 2005.

Jacobsen, I. and Heise, E.: A new economic method for the computation of the surface temperature in numerical models, Beitr. Phys. Atmosph., 55, 128-141, 1982.

Jarvis, P. G.: The interpretations in the variations in leaf water potential and stomatal conductance found in canopies in the field, Philosoph. Trans. R. Soc., London Ser. B, 273, 593-610, 1976.

Kerschgens, M., Pilz, U., and Raschke, E.: A modified two-stream approximation for computations of the solar radiation budget in a cloudy atmosphere, Tellus, 30, 429-435, 1978.

Kessler, E.: On the Continuity and Distribution of water substance in the atmospheric circulation, Meteorological Monographs, Vol. 10, No. 32, Amer. Meteorol. Soc., Boston, 1969.

Laprise, R.: Resolved scales and nonlinear interactions in limitedarea models, J. Atm. Sci., 60, 768-779, 2003.

Louis, J.-F.: A parametric model of vertical eddy fluxes in the atmosphere, Boundary-Layer Meteorol., 17, 187-202, 1979.

Nezlin, N. P. and Stein, E. D.: Spatial temporal patterns of remotelysensed and field-measured rainfall in southern California, Rem. Sens. Environ., 96, 228-245, 2005.

Noguer, M., Jones, R., and Murphy, J.: Sources of systematic errors in the climatology of a regional climate model over Europe, Clim. Dyn., 14, 691-712, 1998.

Noilhan, J. and Planton, S.: A simple parameterization of land surface processes for meteorological models, Mon. Wea. Rev., 117, 536-549, 1989.

Nordeng, T. E.: Extended versions of the convection parameterisation scheme at ECMWF and their impact upon the mean climate and transient activity of the model in the tropics, Res. Dep. Tech. Memorandum, No. 206, ECMWF, Reading, UK, 1994.
Redelsperger, J. L. and Sommeria, G.: Three-dimensional simulation of a convective storm: Sensitivity studies on subgrid parameterization and spatial resolution, J. Atmos. Sci., 43, 2619-2635, 1986.

Ritter, B. and Geleyn, J.-F.: A comprehensive radiation scheme for numerical weather prediction models with potential applications in climate simulations., Mon. Wea. Rev., 120, 303-325, 1992.

Roache, P. J.: Computational fluid dynamics, Hermosa Publishers, Albuquerque, New Mexico, 446 pp., 1972.

Sogalla, M. and Kerschgens, M.: Berechnung lokaler Niederschlagsfelder zur Parameterisierung der nassen Deposition auf der Basis größer-skaliger Wettervorhersagemodelle, Mitteilungen aus dem Institut für Geophysik und Meteorologie der Universität zu Köln, 144, Appendix A (in german, with english Appendix), 2001.

Sommeria, G. and Deardorff, J. W.: Subgrid-scale condensation in models of nonprecipitating clouds, J. Atmos. Sci., 34, 344-358, 1977.

Sundquist, H.: Parameterization of condensation and associated clouds for weather prediction and general circulation simulation, in: Physically-based modelling and simulation of climate and climate change Part I, edited by: Schlesinger, M. E., NATO ASI series, 243, Kluwer Acad. Pub. Dordrecht/Boston/London, 433464, 1988

Tiedtke, M.: A comprehensive mass flux scheme for cumulus parameterization in large-scale models, Mon. Wea. Rev., 117, 1779-1800, 1989.

von Storch, H., Langenberg, H., and Feser, F.: A Spectral Nudging Technique for Dynamical Downscaling Purposes, Mon. Wea. Rev., 128, 3664-3673, 2000.

Warner, T. T., Peterson, R. A., and Treadon, R. E.: A tutorial on lateral boundary conditions as a basic and potentially serious limitation to regional numerical weather prediction, Bull. Amer. Meteorol. Soc., 78, 2599-2617, 1997.

Wu, W., Lynch, A. H., and Rivers, A.: Estimating the uncertainty in a regional climate model related to initial and lateral boundary conditions, J. Clim., 18, 917-933, 2005. 